\title{
Different Aspects of Changes in Wholesale Price Index (WPI) and Consumer Price Index (CPI) and Indian Economy
}

\author{
Jitesh Chandra Saha \\ Govt. Degree College, Kamalpur, Dhalai, Tripura, India
}

\begin{abstract}
Different pattern of trend in WPI and CPI numbers over years is found to be depicted periodically for Indian economy. This has implication for casting impact on supply price determination while purchasing power of consumers can be chalked about from trend in their per capita income which also demonstrates variation over years. Movement of these indices may focus on ongoing changes taking place in exchange activities as well as may point towards price determination mechanism operating in economic system. An effort has been made in preparing framework of this paper to analyse and explore various contemporary socio-economic changes ushered in by movement of WPI and CPI indices over years and its impact fell on nature of transaction, places of transaction and network of transaction.
\end{abstract}

Keywords: price indices, price determination, agglomeration, economic transaction

\section{Introduction}

Recently food inflation was reigning throughout most part of this globe with a sustainable trait (Newton, 2008) and in India, aggregate experience was no exception to that trend. No doubt about the notion that food is a marketable commodity although for some producers after maintaining subsistence, rest supplied to market may be zero and negative. Without food intake energy generation is not possible to remain active and this distinguishes food articles from other commodities in which right of consumption gets transferred from producers to consumers. Then adjustment through invisible hands needs certain additional considerations for satisfaction of both producers and consumers to happen actually for these types of commodities. This leads to realisation that commodity specific arrangements (Mousseau, 2010) should be undertaken for valuation process, its continuity within acceptable tenacity and universal availability as well as arrangement for buffering to outweigh adversities needs to be present (Basu, 2010). From this perspective when recent phenomenon of value fluctuation is looked into, it becomes evident that essential necessity as a factor is lacking vigour to enter into criterion and prevalence of some other arrangement leading to unbridled rise in valuation of food and declining trend in that of accessories like ornament materials. This implies quantum of resources spent to make today's pattern of interaction is becoming relatively lower than that to generate required productive energy for utilising those. This puts a question to basic thought whether human being will bear more comparative cost for survival than that for its correlatives. Under extreme circumstances this may also materialise that even though you

Jitesh Chandra Saha, assistant professor of Economics, Govt. College Degree, Kamalpur, Dhalai, Tripura, India.

Correspondence concerning this article should be addressed to Jitesh Chandra Saha, Department of Economics, Govt. Degree College, Kamalpur, Garad Tilla, Harerkhola, Dhalai, Tripura 799285, India. 
possess those commodities but these remain unutilised just because you do not have physical and mental chi for not taking into judgement criterion the distinction between bare necessity and necessity and more valuation is imputed to necessity without which people can air than that without which they lack calories to live.

\section{Participant Outlook}

Producers may participate in exchange activities only after satisfying their own subsistence as well as may find cost effectiveness in transferring ownership right from beginning and resources such obtained may fulfil other necessities of daily life. From macro economic consideration, equilibrium necessitates deployment of resources in a way so that after fulfilling internal requirements feasibly, policy for external sector can be pursued. Alternative initiatives can also be undertaken in which exchange between internal and external sector may take place to generate resources for attaining stage of domestic fulfilment without untenable value fluctuation. This has practical implication especially for an essential necessity as there would be no violent volatility of price level and erosion in affordability of domestic consumer. Then for a food self-sufficient economy it needs sudden upheaval, lack of priority focus and emergency operation arrangement to have unbearable inflation in economic sector producing life essentials. Standing on such platform reckless global food inflation seems to be pointing towards those possibilities in lacking significance of first human need (MSSRF and FAO, 2008), really surprising when we term present world of human civilisation modernised after passing over thousands and thousands of years since primitive ages.

\section{Preparation for Potential Development}

Hypothesising surplus output disposed off to meet needs of external economy, persistence of faster rise in monetary standard of a particular commodity at least could be made to crawl comparatively at lower pace, had there been buffer stock operation and regulated justification for external sector (IMF, 2008). This implies consumers might have been sustaining their affordability by purchasing similar consumption basket at relatively lower resource level. Henceforth for such essential commodities an economy may continue striving forward with higher tolerance level in form of lower monetary valuation but occurrences may just be the opposite and this wedge between these two tolerance levels will nurse a potential monetary differential which may influence further course of economic development. New enterprising initiatives may emerge with soft terms of easily accessible institutional finance and this may put forward to another kind of agglomeration with different circulation process for market participants in transaction activities and a new constellation in entire exchange execution (Johansson, Borje, \& Quigley, 2004). For new enterprisers potential monetary differential may provide an incentive to come forward with well furnished arrangements for serving consumer needs while for consumers additional burden may not be felt in moving there elated and placing their demands at pre-determined level. Such inflationary trend may also be observed as present level of developmental cost incurred for preparing future trajectory of economically advanced stage (Singh, 2011). This brings in location change by forming new agglomeration of exchange activities in new areas with completely different structure while accessing older agglomerations may be diminished and turn obsolete, even some may get disappeared. Like other investment projects these initiatives also may get concentrated in areas equipped with required infrastructures (Crawford, 2006), and may add another feather to cultural variations between urban and rural agglomerations in respect of market participation. While rural transaction is accomplished in open air space under particular time-schedule, urban exchange process is gradually becoming confined to closed ones as long 
as time permits. This type of market stratification may even crop up in urban areas where newly formed enclave is accessed by certain section of urban population while others continue to pursue their traditional mode of transaction with previous constellations (Duranto \& Puga, 2003). Some producers earlier having direct contact with consumers presently may be part of supply chains to provide new enterprises acting as intermediaries and financially sound static mediator may co-exist with the dynamic ones in new form of development. Price setting mechanism may be determined by these new classes through transferring operation from invisible hands (Fujita \& Thisse, 2002), and with change in nature of contact real market participants may become further apart. on one hand if there is awareness lack of real consumers, then output valuation measurement may not be holistic while on the other hand, due to inability in estimating market demand, urge for aggregated effort particularly that of real producers may turn scattered and linked to areas backyard to newly formed agglomerations.

\section{A Look Into the WPI Trend}

Over years trend in movement of Indian WPI reveals a pattern which was not predominant during initial decades of planning but became general feature of later decades. This can point towards shift in economic principle and that in required machinery governing economy from its involvement in other activities of beginning years. Fluctuations in annual average WPI of all commodities particularly food articles can be grouped on basis of degree of intensification into prevalence of higher expectation realisation and following lower turn in rate of change. Greater rate of changes are clustered around beginning of cyclical activity years whereas another cluster of relatively slower variation is found to be formed at terminal sub-periods (Figure 1).

As factors leading to its operation are found to exhibit dynamic continuation this movement pattern in WPI showing scatterings during earlier years may produce a general trend. This implies functioning of mass scale market participants propelled by economic and non-economic factors finds it viably meaningful at certain sub-periods to gear up rate of advancement in exchange value at proportionately higher level than that at subsequent sub-periods. Rationality in objectivity needs to be time independent with adjustment parameters for calamities and must have property of continuity. From this viewpoint it becomes evident that through adoption of variable viability criterion, wholesale producers do not worry about following higher rate of WPI advancement at certain sub-periods while in next sub-period they become succumbed to fear about possibility of having an uncontrollable turbulence (FAO, 2010) that may impede normal course of economic functioning and choose path of progress at a lower per se. This may also imply that there is uneven distribution of information and awareness between two broad classes of market participants leading to the outcome where platform of one segment may be at advantage and seen to acquire more strength than that of other segment during initial sub-period of a cyclical time-frame while during its later sub-period that very segment administers price determination other way round not on basis of economic reasoning and representation but to maintain smooth functioning of economic system, showing real looseness picture of their aggregate character. This behaviour of WPI over time is found to prevail not only for aggregate commodity bundle but also for disaggregated commodities and within this category, WPIs of food-articles with comparable bases and periodic exceptions are getting surpassed those of non food-articles (Roy, 2013), although weights for former articles in consumption basket are almost five times higher than that for consumable latter articles. 

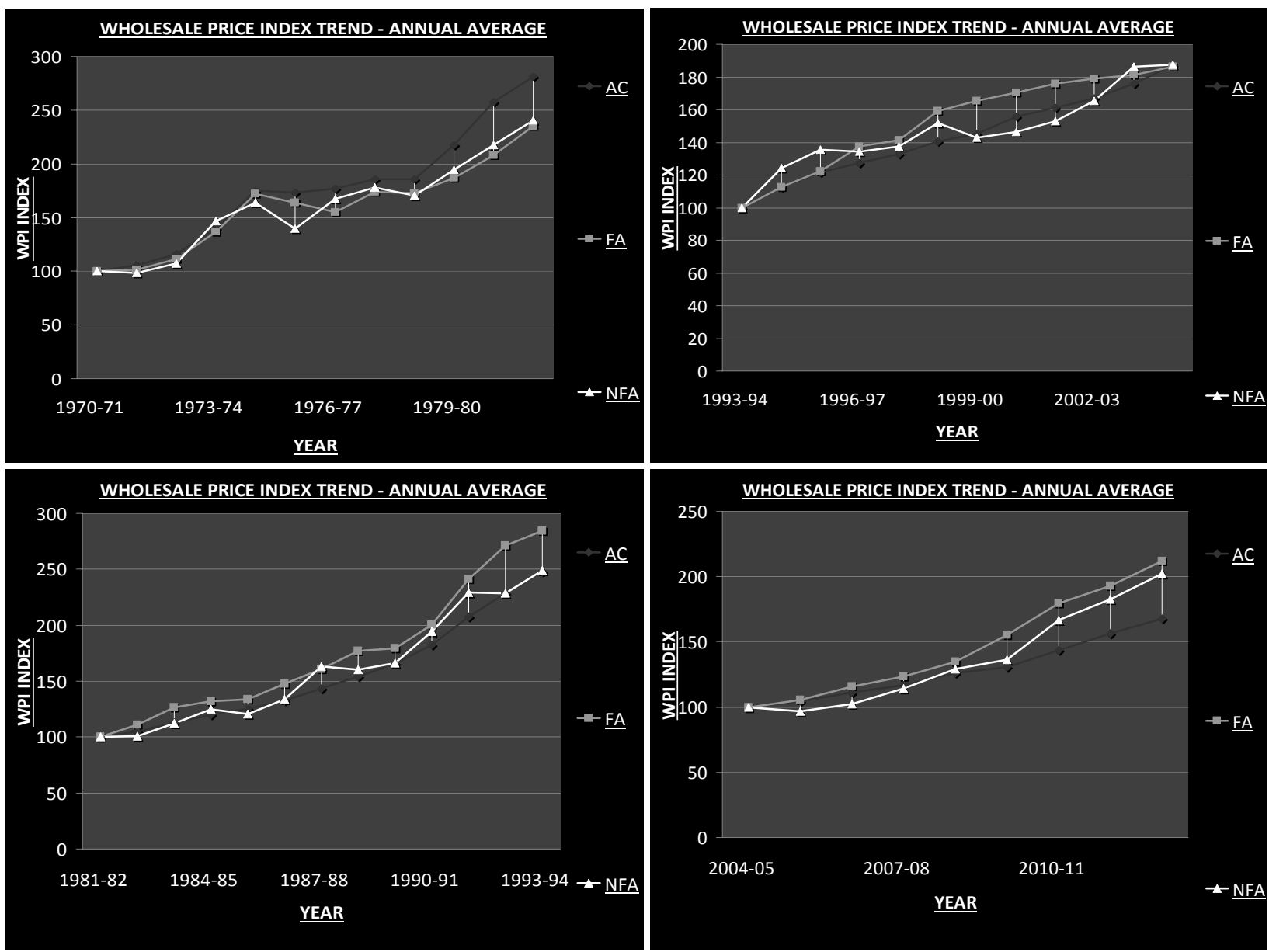

Figure 1. Wholesale price index pattern of India. Source: Labour Bureau, CSO, Government of India, AC-All Commodities, FA-Food Articles and NFA-Non-Food Articles.

\section{Other Side - The CPI}

As consumption expenditure increases less than proportionately to income level, average propensity to consumption (APC) and marginal propensity to consumption (MPC) show declining trend, consumption needs require a greater share of income for that stratum of people residing at the base of income pyramid compared to others occupying the uppermost level and in between these two extremes, inverse relationship prevails. It is evident that APC will certainly be higher for downtrodden and labour section of population of an economy particularly in agricultural sector where earned income is discontinuous, making fulfilment of their family expenses difficult to sustain throughout year and that further depends on vagaries of monsoon and other adverse circumstances outside their control. Its reflection should be present in setting consumer prices and regulating fluctuation to such an extent that hardship faced by different section of people in maintaining their acquired consumption standard are not burdened further. Alias status quo level can be maintained and there may be a possibility to materialise when change in earnings expressed through Gross National Product (GNP) and Net National Product (NNP) at factor cost per capita changes becomes higher than that of CPI movements due to favourable economic situation. But found trend in GNP and NNP at factor cost per capita makes a pattern contrary to that of Indian WPI and CPI, implying extremities and periodical intensification of economic comfort and discomfort distinctively from the end of third decades of planning years (Figures 1, 2, and 4). 
Similar findings are mathematically obtained in following trend regression and cyclical filters with further clarity. After uniforming base period, logarithm of per capita net national product at factor cost [log (PCNP)] shows the following trend $(\mathrm{T})$ equation:

$$
\log (\mathrm{PCNP})=-56.845+0.03 \mathrm{~T}
$$
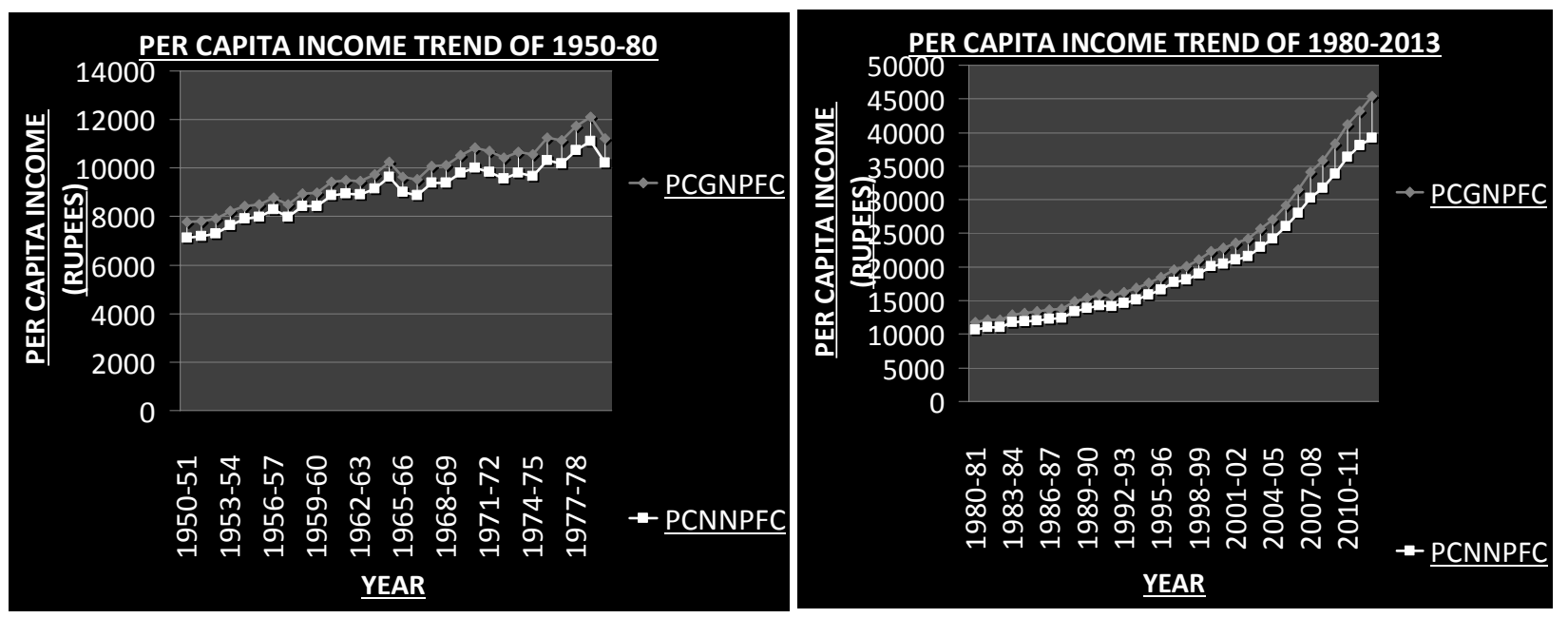

Figure 2. Per capita gross and net income pattern of India. Source: Reserve Bank of India, PCGNPFC-Per Capita GNP at Factor Cost and PCNNPFC-Per Capita NNP at Factor Cost.

Whereas,

$$
\log (\mathrm{AC})=-137.63+0.07 \mathrm{~T}
$$

Equation (2) shows trend regression for wholesale price of all commodities (AC).

Cyclical components extracted from residuals of equations (1) and (2) through Eviews Baxter-King symmetric filter depict negative correlation as shown below in form of area diagram (Figure. 3):

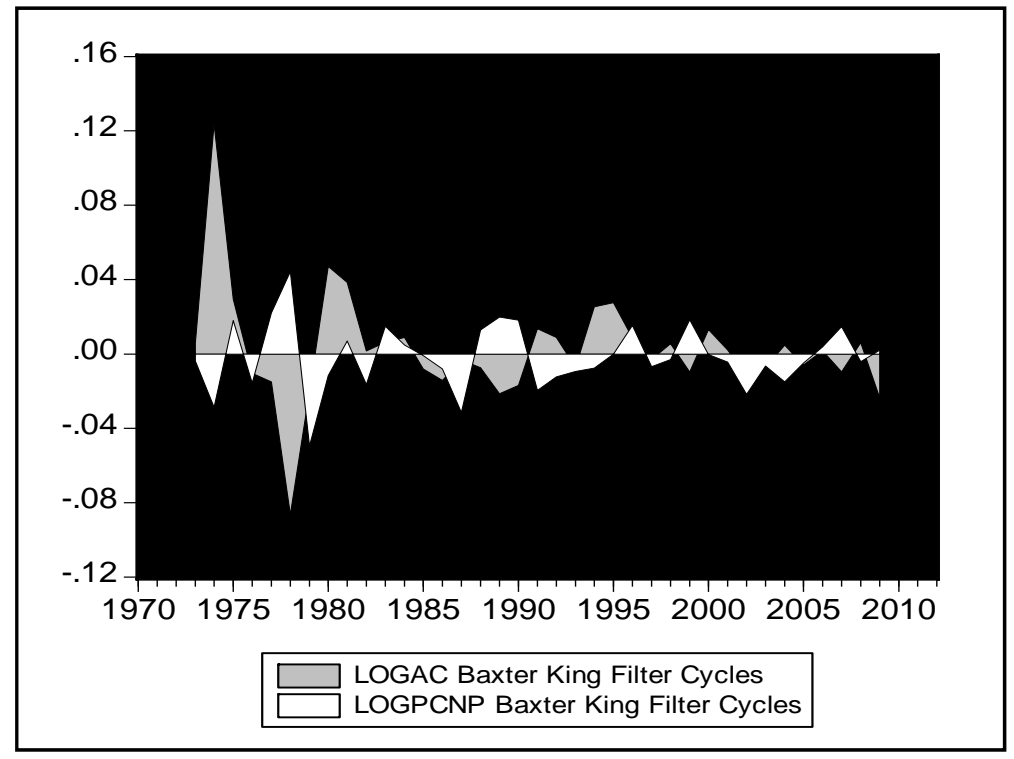

Figure 3. Cyclical fluctuation.

Similar relationship is found to be formed by CPI for agricultural labour. 
Changes in available statistics on CPI for different category of bread earners such as agricultural labourers, industrial workers and urban non-manual employees for specified time intervals reveal that this index number has moved faster for those section of consumers with higher consumption propensities compared to that of other sections (Figure 3). Another category of divergence observed between rural and urban economy is that although consuming similar commodity bundles, it is for rural people being real producer of directly consumable basic commodities than that for its urban counterpart mostly satisfied with such basic supply, maintenance of sustenance leaving aside under-feeding and under-nourishment, is becoming dearer (Randy, Schnepf, Joe, \& Richardson, 2009). Similar to periodic movement of WPI which further is amenable to sub-divided periods of different degree of change, fluctuations in CPI also follow sub-periods of greater change and subsequent mildness but aggregate trend is upward rising (Figure 4).

Keeping in mind that in India there is agricultural self-sufficiency with few exceptional years of floods and droughts, continuous participation in external trade along with presence of buffer stock operation and outlet through public distribution network (Virmani, Arvind, \& Rajeev, 2001), this leads us to other side of phenomenon occurring for market participants in last three and four decades that at beginning of a cyclical period consumers may experience faster rise in monetary value of their purchased leading to a speedy decline in their affordability and enhancing possibilities of collective plea for protecting their interest while after outturn of that sub-period consumers are imbued economic relief as they pass through a interval of comparatively lower rate of decline in values of their resources and perceive improvement in their purchasing power getting prepared for next cyclical proceedings as they do not feel urge to proceed with same intensity in order to prevent cyclical price rise.
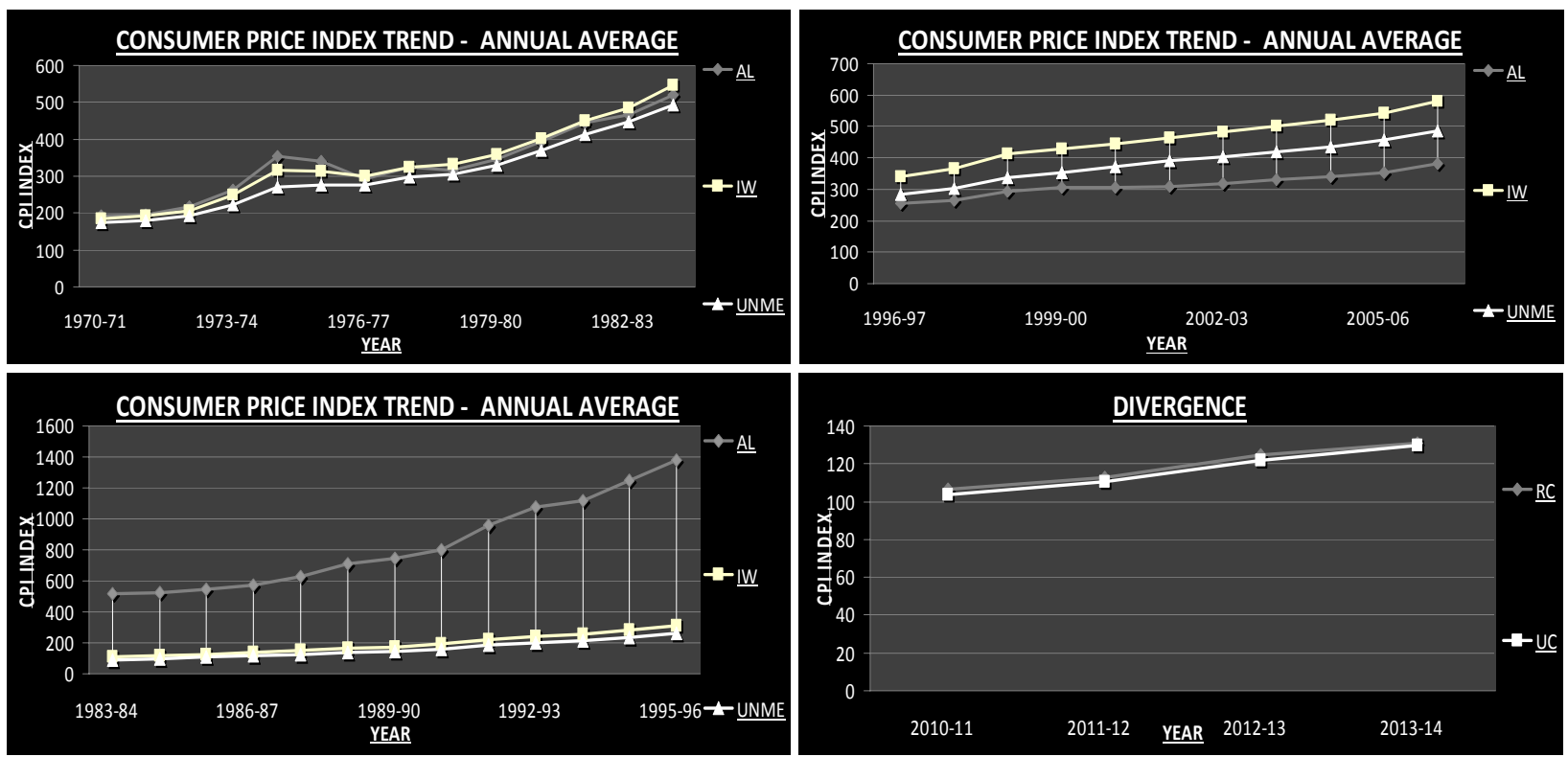

Figure 4. Consumer price index pattern of India. Source: Labour Bureau, CSO, Government of India, AL-Agricultural Labour, IW-Industrial Worker and UNME-Urban Non-Manual Employee.

\section{Conclusion}

From an extended viewpoint all are involved in economic transaction activities. Compared to other sort of market participation everyone ends up with coming under different types of consumers for essential 
commodities sometimes termed as rainbow of consumerism and the platform they constitute, derives its huge motive power from the basis spanning their vastness as well as their progress forward become attributed with property of time, place, gender, ethnicity and any other consideration invariance. This has potentiality of universal application and can be reinstated as a common place for orientation of world inhabitants at aggregate providing greater inward thrust to raise louder voice than any other platform in order to protect not only their basic needs but also any other reasonable economic interest for maintaining affordability and sustainability (Urgate \& Murphy, 2008). From this perspective along with presence of associative thinking, persuasion, even distribution of information, sheer awareness and subsequent action under proper guidance and direction can adorn Consumer Awareness programme with real ingredients interpreted in terms of meaningful and successful implementation on ground. This may give rise to a possibility that difference no longer may exist between drive to mass consumerism and required affordability, otherwise show may be there but right to see by maintaining spectator economic capacity may become limited.

\section{References}

Basu, K. (2010). The economics of foodgrains management in India. Ministry of Finance, New Delhi: Government of India.

Crawford, R. (2006). The effects of agglomeration on economic activity: The empirical evidence on mechanisms and magnitudes. Occasional Paper 06/03. New Zealand: Ministry of Economic Development.

Duranton, G., \& Puga, D. (2003). Micro-foundation of urban agglomeration economies. In J. V. Henderson and J-F. Thisse (Eds.), Handbook of regional and urban economics (p. 4). Holland: North.

FAO. (2010). Fighting food inflation through sustainable inflation. London: FAOEBRD.

Fujita, M., \& Thisse, J-F. (2002). Agglomeration and market interaction. Institute of Economic Research, Japan: Kyoto University.

IMF. (2008). Food and fuel prices-recent developments, macroeconomic impact, and policy response. Washington D.C.: Fiscal Affairs, Policy Development and Review, and Research Department.

Johansson, B., \& Quigley, J. M. (2004). Agglomeration and networks in spatial economies. Regional Science, 83.

Mousseau, F. (2010). The high food price challenge: A review of responses to combat hunger. USA: The Oakland Institute.

MSSRF and FAO. (2008). Report on the state of food insecurity in rural India, fiscal affairs. Chennai: M.S. Swaminathan Research Foundation, 9-10.

Newton, A. (2008). The politics of food price inflation, geopolitics. New York: Lehman Brothers Inc.

Randy, S., \& Richardson, J. (2002). Consumers and food price inflation. Congressional Research Service, Report-R40545.

Roy, S. S. (2013). Recent inflation: Inflation or price rise. Arthabisleson, I(I).

Singh, S. (2011). FDI in retail: Misplaced expectations and half-truths. Economic and Political Weekly, XLVI(51).

Urgate, D., \& Murphy, S. (2008). The global food crisis: Creating an opportunity for fairer and more sustainable food and agricultural systems worldwide. Discussion Papers No. 11. Berlin, Misereor and Heinrich-Boll-Stiftung.

Virmani, A., \& Rajeev, P. V. (2002). Excess food stocks, PDS and procurement policy. Working paper No. 5/2002. Planning Commission, New Delhi: Government of India. 